(C) 2021, The Authors. Published by Elsevier Inc. and Fass Inc. on behalf of the American Dairy Science Association ${ }^{\circledR}$. This is an open access article under the CC BY-NC-ND license (http://creativecommons.org/licenses/by-nc-nd/4.0/).

\title{
Adenosine 5'-monophosphate-activated protein kinase ameliorates bovine adipocyte oxidative stress by inducing antioxidant responses and autophagy
}

\author{
Qiushi Xu, ${ }^{1}$ ๑ Yunhui Fan, ${ }^{1}$ Juan J. Loor, ${ }^{2}$ ๑) Yusheng Liang, ${ }^{2} \odot$ Xudong Sun, ${ }^{1}$ Hongdou Jia, ${ }^{1}$ Chenxu Zhao, ${ }^{1}$ \\ and Chuang $\mathrm{Xu}^{1 *}$ (ㅇ) \\ ${ }^{1}$ College of Animal Science and Veterinary Medicine, Heilongjiang Bayi Agricultural University, Daqing, China 163319 \\ ${ }^{2}$ Mammalian NutriPhysioGenomics, Department of Animal Sciences and Division of Nutritional Sciences, University of Illinois, Urbana 61801
}

\begin{abstract}
Adipose tissue concentration of reactive oxygen species (ROS) increases in dairy cows with ketosis, suggesting that the tissue experiences oxidative stress. Autophagy, an adaptive response to cellular stress, has been shown to promote survival and plays a critical role in antioxidant responses. Dysregulation of adenosine $5^{\prime}$-monophosphate-activated protein kinase (AMPK) is closely related to antioxidant responses and autophagy of adipocytes in animal models of metabolic disorders, but its role in bovine adipose tissue during periods of stress is unknown. We hypothesized that AMPK may play important roles in the regulation of oxidative stress in adipose tissue of ketotic cows. Specific objectives were to evaluate autophagy status and AMPK activity in adipose tissue of ketotic cows, and their link with oxidative stress in isolated bovine adipocytes. Selection of 15 healthy and 15 clinically ketotic Holstein cows at $17( \pm 4)$ d postpartum was performed after a thorough veterinary evaluation for clinical symptoms and also based on serum $\beta$-hydroxybutyrate concentrations before collection of subcutaneous adipose tissue samples. Primary cultures of bovine adipocytes isolated from the harvested adipose tissue were stimulated with varying concentrations of $\mathrm{H}_{2} \mathrm{O}_{2}(0,50,100,200$, or $400 \mu M)$ for $2 \mathrm{~h}$. In another experiment, adipocytes were cultured with the AMPK activator A769662 or adenoviruscontaining small interfering RNA (ad-AMPK $\alpha$-siRNA) for 3 or $48 \mathrm{~h}$, respectively, followed by $\mathrm{H}_{2} \mathrm{O}_{2}$ exposure $(200 \mu M)$ for 2 h. Compared with healthy cows, clinical ketosis led to increased abundance of AMPK and nuclear factor erythroid-derived 2-like 2 (NFE2L2), but lower abundance of Kelch-like ECH-associated protein 1 (KEAP1) in adipose tissue. Abundance of the key proautophagy proteins Beclin1, sequestosome 1 (SQSTM1), autophagy-related gene 7 (ATG7), ATG5, and ratio of
\end{abstract}

Received April 16, 2020.

Accepted November 7, 2020.

*Corresponding author: xuchuang7175@163.com microtubule-associated protein light chain 3 (LC3) II to LC3I were greater in adipose tissue of ketotic cows. In bovine adipocytes, treatment with $\mathrm{H}_{2} \mathrm{O}_{2}$ induced accumulation of ROS and malondialdehyde (MDA), whereas $\mathrm{H}_{2} \mathrm{O}_{2}$ stimulation inhibited activities of the antioxidant enzymes glutathione peroxidase (GSH-Px) and superoxide dismutase (SOD). Addition of AMPK activator A769662 increased antioxidant response via activating NFE2L2 and its downstream targets heme oxygenase 1 (HMOX1), superoxide dismutase 1 (SOD1), catalase (CAT), and glutathione-S-transferase (GST) to improve $\mathrm{H}_{2} \mathrm{O}_{2}$-induced oxidative stress in adipocytes. Simultaneously, activation of AMPK increased abundance of Beclin1, SQSTM1, ATG7, ATG5, and ratio of LC3II to LC3I. In contrast, inhibition of AMPK downregulated abundance of NFE2L2, HMOX1, SOD1, CAT, Beclin1, SQSTM1, ATG7, ATG5, and ratio of LC3II to LC3I, and further aggravated $\mathrm{H}_{2} \mathrm{O}_{2}$-induced oxidative stress. Overall, these data indicate that activation of AMPK, as an adaptive mechanism for acute metabolic regulation of adipose tissue homeostasis, can induce antioxidant responses and autophagy, and further reduce oxidative stress in bovine adipocytes.

Key words: adipocytes, NFE2L2, AMPK, autophagy

\section{INTRODUCTION}

The transition between late gestation and the onset of lactation is a physiologically challenging period for dairy cows and is the predominant time when metabolic disorders occur (Goff and Horst, 1997; Drackley, 1999; Loor et al., 2013). Ketosis is a major metabolic disorder of transition dairy cows and is characterized by increase in blood and milk concentrations of BHB and free fatty acids resulting from adipose tissue lipolysis (Loor et al., 2007; Van der Drift, 2013). Multiple studies have underscored the essential metabolic adaptations occurring in adipose tissue to support lactation, with lipolysis and remodeling being the most studied (McNamara, 1994; Vernon, 2003; Contreras et al., 2017). More recent data from ketotic cows indicated that excessive 
production of reactive oxygen species (ROS) during high lipolytic rates may overwhelm the existing antioxidant defense mechanisms and further induce oxidative stress in adipose tissue (Sun et al., 2019). However, beyond antioxidant responses, mechanistic alterations within adipose tissue during ketosis are not well known.

Autophagy, an adaptive response to cellular stress, is essential in performing cell quality control by eliminating damaged organelles to maintain homeostasis (Kroemer et al., 2010). Recent studies have showed that dysfunction of autophagy contributes to the pathology of various diseases, including cancer, neurodegenerative disorders, and diabetes (Mizushima and Komatsu, 2011). Thus, regulation of autophagy might be an effective therapeutic target (Fleming et al., 2011). In dairy cows, autophagy is altered during metabolic disorders in the transition period. Enhanced autophagic activity in the liver and mammary gland has been associated with response mechanisms to alleviate metabolic stress induced by mild fatty liver and hyperketonemia (Chen et al., 2020; Li et al., 2020). At least in nonruminants experiencing metabolic disorders associated with adipose tissue dysfunction, autophagy is stimulated by oxidative stress (Zhang et al., 2012; Mizunoe et al., 2017). A previous study reported that impaired liver autophagy activity in cows with severe fatty liver was associated with inflammation and decreased liver function (Du et al., 2018). Hence, the induction of autophagy and antioxidant responses in adipose tissue may contribute to ameliorating oxidative stress during ketosis.

Adenosine 5'-monophosphate-activated protein kinase (AMPK), a key cellular sensor of energy homeostasis, is activated upon stress conditions including nutritional starvation and cellular stress, responding to various physiological hormones and thereby coordinating ATP production and energy demands (Hardie, 2015). In brown adipose tissue, AMPK is required for maintaining mitochondrial function and protecting against metabolic disorders including insulin resistance, hypothermia, and obesity-induced fatty liver disease (Auciello et al., 2014; Day et al., 2017). In addition to its role in mitochondrial content and function, AMPK can also control the development of adipocytes in mice (Zou et al., 2018). A study with mice deficient in AMPK in adipocytes established that this protein is required for maintaining the structure and function of brown adipose tissue, with its ablation leading to defects in antioxidant responses during stress such as cold exposure (Mottillo et al., 2016).

Autophagy can be promoted by AMPK as part of the regulation of cellular metabolism to maintain energy homeostasis (Kim et al., 2011). A previous study demonstrated that diabetic cardiomyopathy is associated with suppression of cardiac autophagy, and activation of AMPK restored cardiac autophagy and prevented cardiomyopathy in mice (He et al., 2013). Collectively, these findings raise the possibility of a link among antioxidant response, the autophagy-mediated protein degradation, and oxidative stress, through the activity of AMPK.

The present study was undertaken to examine the antioxidant and autophagy processes during oxidative stress in adipose tissue of ketotic cows. We specifically tested the hypothesis that AMPK reduces oxidative stress in bovine adipocytes through molecular upregulation of antioxidant responses and autophagy-related proteins.

\section{MATERIALS AND METHODS}

\section{Animals}

All animal procedures were performed in accordance with the Guidelines for the Care and Use of Experimental Animals in Heilongjiang Bayi Agricultural University (Daqing, China). The Animal Ethics Committee of Heilongjiang Bayi Agricultural University approved the study protocol (SY201809005). Holstein dairy cows selected in this experiment were from a 7,000-cow dairy farm with a freestall housing system located in Nenjiang city (Heilongjiang, China). A total of 180 lactating Holstein cows (number of lactations: median $=3$, range $=2$ to 4; DIM: median $=17 \mathrm{~d}$, range $=12-21 \mathrm{~d}$ ) were tested to identify ketotic and healthy animals between September and October 2018. All cows were examined to ensure no other complications, such as hypocalcemia or mastitis. Cows testing positive for sodium nitroprusside ketone bodies in milk were classified by veterinarians as suspected clinically ketotic. Body condition was scored by the same herd veterinarian using a 5 -point scale $(1=$ emaciated to $5=$ obese; Ferguson et al., 1994). Concentration of BHB in blood of those cows was measured to ascertain ketosis status. Thus, based on clinical symptoms and serum BHB concentration, 15 clinically ketotic cows with serum BHB concentrations above $3 \mathrm{~m} M$ and 15 cows with serum BHB concentrations below $1.2 \mathrm{~m} M$ were randomly selected as the healthy control group (Vanholder et al., 2015). Blood samples were collected between 0700 and $0800 \mathrm{~h}$ before feeding, using jugular vein puncture without anticoagulant. Samples were allowed to clot at room temperature for $2 \mathrm{~h}$ and centrifuged at $1,900 \times g$ for $15 \mathrm{~min}$ to separate serum at $4^{\circ} \mathrm{C}$. A Hitachi 7170 automatic analyzer (Hitachi Laboratory Measurement, Tokyo, Japan) and commercially available kits (Randox Laboratories, Crumlin, UK) were used to detect serum concentrations of glucose (cat. no. GL3815), serum free fatty acids (cat. no. FA115), and BHB (cat. no. RB1008). 
Table 1. Baseline characteristics of the dairy cows and samples used in this study ${ }^{1}$

\begin{tabular}{lccc}
\hline Characteristic & Control $(\mathrm{n}=15)$ & Ketosis $(\mathrm{n}=15)$ & $P$-value \\
\hline Parity & 3 & 3 & \\
Milk production $(\mathrm{kg} / \mathrm{d})$ & $38.34 ; 1.03$ & $27.50 ; 0.82$ & 0.001 \\
BW $(\mathrm{kg})$ & $613.29 ; 41.31$ & $643.70 ; 16.51$ & 0.003 \\
DMI $(\mathrm{kg} / \mathrm{d})$ & $21.32 ; 0.51$ & $19.75 ; 0.82$ & 0.015 \\
BCS & $2.67 ; 0.25$ & $3.32 ; 0.25$ & 0.023 \\
Serum BHB $(\mathrm{m} M)$ & $0.50 ; 0.14$ & $4.11 ; 0.08$ & 0.003 \\
Serum free fatty acids $(\mathrm{m} M)$ & $0.30 ; 0.06$ & $1.05 ; 0.05$ & 0.001 \\
Serum glucose $(\mathrm{m} M)$ & $3.72 ; 0.34$ & $2.13 ; 0.23$ & 0.001 \\
\hline
\end{tabular}

${ }^{1}$ Data were analyzed using the Wilcoxon test. Data are presented as median and interquartile range.

Physiological parameters of ketotic and healthy cows are presented in Table 1. All animals were fed the same diet during the dry period, and the diet was formulated to meet the National Research Council recommendations (NRC, 2001). During lactation, all animals were fed the same diet to requirements (NRC, 2001). The nutrient composition of dry and lactating cow rations is reported in Supplemental Table S1 (https://dataverse. harvard.edu/dataset.xhtml?persistentId=doi:10.7910/ DVN/BA8WO4).

\section{Adipose Tissue Collection and Processing}

Subcutaneous adipose tissue was collected at $17( \pm 4)$ $\mathrm{d}$ postpartum from the tail-head depot of all cows on the same day through the methods described previously (Xu et al., 2019b). In brief, the pelage on the tail-head region and one side of the tail-head were thoroughly scrubbed with surgical soap before tissue collection. Local anesthesia was administered in the area between the ischium and tailbone. A scalpel incision of about 6 to 8 $\mathrm{cm}$ was made and the skin pulled with sterile forceps and hemostats to expose the tissue. Adipose tissue samples (1 to $2 \mathrm{~g}$ ) were collected using sterile scalpel blades and forceps. After sampling, compression hemostasis was applied with sterile gauze to prevent any external bleeding. The sampling incision was sutured with 8 to 12 surgical staples (Henry Schein, Melville, NY). Adipose tissue samples were washed with sterile PBS. Adipose tissue samples for total protein extraction were weighed and stored in cryotubes (cat. no.5000-0050; Nalgene, Milwaukee, WI) and then placed into liquid nitrogen. Adipose tissue samples for preadipocyte isolation were stored in culture medium bottles (cat. no. 342040-0650; Nalgene) with sterile PBS containing penicillin $(2,500$ $\mathrm{U} / \mathrm{mL})$ and streptomycin $(2,500 \mathrm{mg} / \mathrm{mL})$.

Isolation of preadipocytes in healthy transition dairy cows was performed according to previously published methods (Zhang et al., 2018a; Sun et al., 2019; Xu et al., 2019a). No preadipocytes were isolated from ketotic cows. In brief, adipose tissue $(1 \mathrm{~g})$ was digested with collagenase type I digestion solution $(1 \mathrm{mg} / \mathrm{mL}$; Sigma-
Aldrich, St. Louis, MO) and then filtered through a 40$\mu \mathrm{m}$ cell filter (Solarbio, Beijing, China). The stromal vascular cells were then centrifuged at $800 \times g$ for 10 min to separate primary preadipocytes from stromal vascular cells. Residual erythrocytes in the resulting cell pellet were eliminated by ammonium-chloridepotassium (ACK) lysis buffer (Solarbio, Beijing, China) and then sequentially centrifuged at $800 \times g$ for 10 min. After discarding supernatant, the resulting pellet was resuspended in basic culture medium (BCM) containing DMEM/F12 (HyClone, Logan, Utah), 10\% fetal bovine serum (HyClone), and 1\% penicillin/streptomycin, and incubated at $37^{\circ} \mathrm{C}$ and $5 \% \mathrm{CO}_{2}$ for $24 \mathrm{~h}$. The medium was then replaced to remove nonadherent cells and tissue debris. Lastly, the culture medium was replaced every $48 \mathrm{~h}$.

\section{Cell Differentiation and Treatment}

To differentiate primary preadipocytes, 5 -d postconfluent cells were incubated in differentiation culture medium 1, containing $10 \%$ fetal bovine serum (HyClone), $1 \%$ penicillin/streptomycin, $0.5 \mathrm{~m} M$ 3-isobutyl-1-methylxanthin (Sigma-Aldrich), $1 \mu M$ dexamethasone (Sigma-Aldrich), and $1 \mu \mathrm{g} / \mathrm{mL}$ insulin (Sigma-Aldrich) in $500 \mathrm{~mL}$ BCM. After $4 \mathrm{~d}$, differentiation culture medium 1 was replaced with differentiation culture medium 2, 1 $\mu \mathrm{g} / \mathrm{mL}$ insulin in $500 \mathrm{~mL}$ of BCM. Two days later, the differentiation culture medium was replaced with BCM for an additional $2 \mathrm{~d}$ (Xu et al., 2019a).

After differentiation, mature adipocytes were treated with $\mathrm{H}_{2} \mathrm{O}_{2}$ (Sigma-Aldrich) at concentrations of 0,50 , 100,200 , or $400 \mu M$ for $2 \mathrm{~h}$. To examine the involvement of AMPK signaling in bovine adipocytes under oxidative stress, the AMPK activator A769662 (1 mM, Sigma-Aldrich) and an adenovirus-containing small interfering RNA (ad-AMPK $\alpha$-siRNA) to inhibit AMPK $\alpha$ were added or transfected to differentiated adipocytes. For the transfection experiments, to silence AMPKo, differentiated adipocytes were transfected with adAMPK $\alpha$-siRNA, and a negative control adenovirus for $48 \mathrm{~h}$. Cells were then treated with increasing concentra- 
tions of $\mathrm{H}_{2} \mathrm{O}_{2}(0,50,100,200$ or $400 \mu M)$ for $2 \mathrm{~h}$. Detailed groupings are indicated in the figure legends. The empty adenovirus vector control and AMPK $\alpha$ inhibition adenovirus (ad-AMPKo-siRNA) were constructed using Gemma Genes (Shanghai, China).

\section{Detection of Oxidative Stress Indicators}

Adipose tissue and adipocyte protein were normalized according to their concentrations and subjected to superoxide dismutase (SOD), glutathione peroxidase (GSH-Px), and malondialdehyde (MDA) assays, as described in the Total Superoxide Dismutase Assay Kit with nitroblue tetrazolium (catalog no. S0109), Total Glutathione Peroxidase Assay Kit (catalog no. S0058), and Lipid Peroxidation MDA Assay Kit (catalog no. S0131S), respectively (Beyotime Institute of Biotechnology, Jiangsu, China). The concentrations of SOD, GSH-Px, and MDA were detected using multimode microplate readers (Multiskan FC, Thermo Fisher Scientific, San Jose, CA) at 560, 340, and $530 \mathrm{~nm}$, respectively. Furthermore, the ROS levels in adipose tissue and adipocytes were determined using Reactive Oxygen Species Assay Kit (catalog no. E004-1-1, NanJing JianCheng Bioengineering Institute, Jiangsu, China) according to the manufacturer's protocols, and detected using multimode microplate readers (Thermo Fisher Scientific) at $520 \mathrm{~nm}$.

\section{Cell Viability Assay}

The MTT Cell Proliferation and Cytotoxicity Assay Kit (C0009, Beyotime Institute of Biotechnology) was used to evaluate cell viability according to the manufacturer's instructions. Bovine adipocytes were seeded at a density of $2 \times 10^{4}$ cells/well (96-well plate) and treated as previously described in the Cell Differentiation and Treatment section. Absorbance was measured at $470 \mathrm{~nm}$ using a 96-well plate reader. Results are expressed as fold-change relative to the control.

\section{Western Blotting}

Western blotting was performed as previously described (Sun et al., 2019). Total protein was extracted from the adipose tissue and adipocytes using a Total Protein Extraction Kit according to the manufacturer's instructions (C510003-0050, Sangon Biotech, Shanghai, China). Briefly, $200 \mathrm{mg}$ of adipose tissue dissolved in precooled $\left(4^{\circ} \mathrm{C}\right)$ lysis buffer containing phosphatase inhibitor, protease inhibitor, and phenylmethylsulfonyl fluoride was homogenized by cryo-milling using a tissue mixer mill at $30 \mathrm{~Hz}$ for 2 min (MM400; Retsch, Haan,
Germany). Tissue homogenates were then centrifuged at $4^{\circ} \mathrm{C}, 15,000 \times g$ for $15 \mathrm{~min}$, to obtain total protein from adipose tissue. For adipocytes, cells were collected from trypsin (25200072; Gibco, Grand Island, NY) digests by centrifugation at room temperature, $800 \times$ $g$ for 5 min. After discarding supernatant, cells were resuspended in precooled lysis buffer, as previously described, and centrifuged at $4^{\circ} \mathrm{C}, 12,000 \times g$ for $5 \mathrm{~min}$, to obtain total protein from adipocytes. Total protein concentration of adipose tissue and adipocytes was measured by the bicinchoninic acid method (C5030510500, Sangon Biotech). A total of $30 \mu \mathrm{g}$ of protein from each sample was separated by $12 \%$ SDS-PAGE (08091, Sigma-Aldrich) with known molecular weight markers (Sangon Biotech). Subsequently, protein was transferred onto $0.45-\mu \mathrm{m}$ polyvinylidene difluoride membranes (IPFL00005, Millipore, Bedford, MA) by wet electroblotting with constant voltage $(80 \mathrm{v})$ for $45 \mathrm{~min}$ in Western blotting transfer buffer ( $25 \mathrm{~m} M$ Tris, 192 $\mathrm{m} M$ glycine with $20 \%$ methanol). The polyvinylidene difluoride membranes were incubated with primary antibodies against AMPK $\alpha(1 \mu \mathrm{g} / \mathrm{mL}$; Ab80039, Abcam, Cambridge, UK), phosphorylation (Thr172) of AMPKo (p-AMPK $\alpha$; 1:1,000; \#2535, Cell Signaling Technology, Danvers, MA), nuclear factor erythroid-derived 2-like 2 (NFE2L2; 1:1,000; 16396-1-AP, Proteintech, Rosemont, IL), Kelch-like ECH-associated protein 1 (KEAP1; 1:2,000, 10503-2-AP, Proteintech), catalase (CAT; 1:2,000, 21260-1-AP, Proteintech), SOD1 (1:1,000, 10269-1-AP, Proteintech), glutathione S-transferase (GST; 1:1,000, Ab111947, Abcam), heme oxygenase (HMOX1; 1:1,000, 10701-1-AP, Proteintech), beclin 1 (1:2,000; Ab92389, Abcam), sequestosome 1 (SQSTM1; 1:2,000, Ab101266, Abcam), autophagy-related gene 7 (ATG7; 1:100,000, Ab52472, Abcam), ATG5 (1:2,000; Ab108327, Abcam), microtubule-associated protein light chain 3 (LC3; $2 \mu \mathrm{g} / \mathrm{mL}, \mathrm{Ab} 128025$, Abcam), and $\operatorname{ACTB}(1: 2,000 ; \mathrm{Ab} 8226, \mathrm{Abcam})$ at $4^{\circ} \mathrm{C}$ overnight. The membrane was then washed with Tris-buffered saline-Tween (TBST) and incubated with the following secondary antibodies: horseradish peroxidase-conjugated Affinipure goat anti-mouse $\operatorname{IgG}\left(\mathrm{H}^{+} \mathrm{L}\right.$; SA00001-1, 1:8,000, Proteintech) or horseradish peroxidase-conjugated Affinipure goat anti-rabbit $\operatorname{IgG}\left(\mathrm{H}^{+} \mathrm{L}\right.$; SA000011, 1:8,000; Proteintech) at room temperature for $1 \mathrm{~h}$. The membrane was then washed with TBST. Immunoreactive bands were then made visible by an enhanced chemiluminescence solution (ECL, Millipore).

The intensity of each band was quantified using ImageJ analysis software (National Institutes of Health, Bethesda, MD). Briefly, after converting the original image to grayscale, a rectangle was drawn over the first lane of the converted Western blot image in a vertical 
direction. After setting the rectangle in place on the last lane, the Plot Lanes function was used to draw a profile plot of each lane. The profile plot represented the relative density of the contents of the rectangle over each lane. The Straight Line selection tool was then chosen from the ImageJ toolbar. For each corresponding peak in the profile plot, a line was drawn across the base of the peak to enclose the peak and obtain the relative intensity value. ACTB was used as internal control to remove gel variation by normalizing abundance of the protein of interest. The normalized intensity was calculated by dividing the intensity of the protein of interest by the intensity of the corresponding internal control obtained from each gel. The mean value of the control group was then calculated, and all other values were divided by that number. Finally, the control group, normalized to 1, was used to obtain the fold-change response.

\section{Immunocytofluorescence}

Bovine adipocytes grown on coverslips were fixed with $4 \%$ (wt/vol) paraformaldehyde for $20 \mathrm{~min}$ at room temperature, as previously described (Xu et al., 2019a). After antigen recovery, cells were incubated overnight with primary antibodies (NFE2L2, Ab31163, Abcam; phosphorylation of SQSTM1, Ab211324, Abcam) diluted 1:200 with goat serum, and then treated with goat anti-rabbit IgG conjugated with Cy3 (Beyotime Institute of Biotechnology) at 1:200 in PBS for $30 \mathrm{~min}$ at room temperature. To analyze immunofluorescence, slides were incubated with fluorescence-conjugated secondary antibodies and 4',6-diamidino-2-phenylindole (DAPI; Beyotime Institute of Biotechnology) in antibody diluent. The coverslips were observed and photographed using a laser scanning confocal microscope (TCS SP2, Leica Microsystems, Wetzlar, Germany).

\section{Statistical Analysis}

Days postpartum of dairy cows used in the study are expressed as mean \pm standard deviation. Baseline characteristics of cows with non-normal distribution are expressed as the median and interquartile range. Other data with normal distribution are expressed as the mean \pm standard error of the mean (SEM). Statistical analysis was conducted using SPSS software version 25.0 (IBM Corp., Armonk, NY) and GraphPad Prism program (Prism 8.3.0; GraphPad Software, San Diego, CA). All data were tested for normality and homogeneity of variance and residuals using the Shapiro-Wilk and Levene tests, respectively. For baseline characteristics of dairy cow data with skewed distribution, non- parametric statistical analysis was performed using the Wilcoxon test (Zhu et al., 2019). Parametric statistical analysis was performed for other data with Gaussian distribution using the independent-samples $t$-test for 2 groups. One-way ANOVA was performed for multiple comparisons with Bonferroni correction. A $P$-value $<0.05$ was considered statistically significant, and a $P$ value $<0.01$ was considered highly significant. In the dose-response study, contrast analysis was conducted to evaluate the linear, quadratic, and cubic effects of $\mathrm{H}_{2} \mathrm{O}_{2}$ on all response criteria except for controls. Differences between means were determined using Duncan's multiple comparisons. Data are presented in tables as means \pm SEM. A $P$-value $<0.05$ was regarded as significant, whereas differences were considered to be a statistical trend when $0.05<P<0.10$.

\section{RESULTS}

\section{AMPKa Abundance, Oxidative Stress, and Autophagy Status in Adipose Tissue}

Compared with the control cows, the phosphorylation of AMPK $\alpha$ at threonine 172 was greater (which led to greater $\mathrm{p}-\mathrm{AMPK} \alpha / \mathrm{AMPK} \alpha$ ratio) in adipose tissue of ketotic cows $(P<0.01$, Figure $1 \mathrm{~A}, \mathrm{~B})$. The protein abundance of NFE2L2 was greater in adipose tissue of ketotic cows $(P<0.01)$, whereas KEAP1 abundance was downregulated in ketotic cows compared with the control cows $(P<0.01$, Figure $1 \mathrm{~A}-\mathrm{C})$. The capacity of the antioxidant enzymes SOD and GSH-Px was downregulated in adipose tissue of cows with ketosis $(P<0.01$, Figure 1D, E). In contrast, the concentration of MDA and ROS in adipose tissue of cows with ketosis was greater compared with controls $(P<0.01$, Figure $1 \mathrm{~F}, \mathrm{G})$. The protein abundance of HMOX1, SOD1, CAT, and GST was greater in the ketosis compared with the control group $(P<0.01$, Figure 1H, I). Protein abundance of factors related to autophagy in adipose tissue is shown in Figure 2. The data indicated that abundance of autophagy-related proteins Beclin1, SQSTM1, ATG7, ATG5 and ratios of LC3II/LC3I in ketotic cows was greater than controls $(P<0.01$, Figure $2 \mathrm{~A}-\mathrm{F})$.

\section{Effects of $\mathrm{H}_{2} \mathrm{O}_{2}$ on AMPKa Abundance and Oxidative Stress Status in Bovine Adipocytes}

The MTT cell viability and cytotoxicity assay revealed significant impairment of cell viability in bovine adipocytes stimulated with 200 to $400 \mu M \mathrm{H}_{2} \mathrm{O}_{2}(P<$ 0.05 ), whereas 50 to $100 \mu M \mathrm{H}_{2} \mathrm{O}_{2}$ had no negative effect on cell viability (Table 2). Compared with the control 
group, treatment of $\mathrm{H}_{2} \mathrm{O}_{2}$ at concentrations of 50 to 400 $\mu M$ caused a linear $(P<0.05)$ dose-dependent lowering effect on SOD and GSH-Px, with a nadir response at $400 \mu \mathrm{M} \mathrm{H}_{2} \mathrm{O}_{2}(P<0.05$, Table 2$)$. In contrast, treatment with $\mathrm{H}_{2} \mathrm{O}_{2}$ increased the concentrations of MDA and ROS in bovine adipocytes in a linear $(P<0.05)$ dose-dependent manner with a peak response at 400 $\mu M \mathrm{H}_{2} \mathrm{O}_{2}$ (Table 2). Compared with the control group, we detected a quadratic effect for NFE2L2 $(P<0.05)$ due to the protein abundance of NFE2L2 increasing gradually with 50 and $100 \mu M \mathrm{H}_{2} \mathrm{O}_{2}$, whereas at 200 and $400 \mu M$ concentrations were lower than the 100 $\mu M \mathrm{H}_{2} \mathrm{O}_{2}$ group (Table 2). A similar quadratic trend was observed in the protein abundance of KEAP1 $(P$ $<0.10)$ and phosphorylation of AMPKo $(P<0.10)$. In addition, a similar dose-dependent quadratic or quadratic trend effect was observed for key downstream targets of NFE2L2, including SOD1 $(P<0.05)$, CAT $(P<0.05)$, HMOX1 $(P<0.10)$, and GST $(P<0.10)$, with the greatest value observed at $100 \mu M \mathrm{H}_{2} \mathrm{O}_{2}(P<$ 0.05, Table 2).

\section{Effects of $\mathrm{H}_{2} \mathrm{O}_{2}$ on Autophagy in Bovine Adipocytes}

The effects of $\mathrm{H}_{2} \mathrm{O}_{2}$ on the abundance of proautophagy proteins [Beclin1, SQSTM1, ATG7, ATG5, and ratio of LC3II to LC3I (LC3II/LC3I)] in bovine adipocytes are shown in Table 3. Compared with the control group, we detected a quadratic effect for SQSTM1 $(P$ $<0.05$ ) due to an increase in abundance at 50 and $100 \mu M \mathrm{H}_{2} \mathrm{O}_{2}$, but a decrease at 200 and $400 \mu M$. The greatest response was observed at $100 \mu M \mathrm{H}_{2} \mathrm{O}_{2}(P<$ 0.05 , Table 3). A similar quadratic trend was observed in the protein abundance of Beclin1 $(P<0.10)$, ATG7 $(P<0.10)$, ATG5 $(P<0.10)$, and LC3II/LC3I $(P<$ 0.10 , Table 3).

\section{Effects of AMPK on Antioxidant Response in Bovine Adipocytes During Exposure to $\mathrm{H}_{2} \mathrm{O}_{2}$}

Compared with the control group, the phosphorylation of AMPK $\alpha$ was upregulated significantly with the treatment of AMPK activator A769662 $(P<$
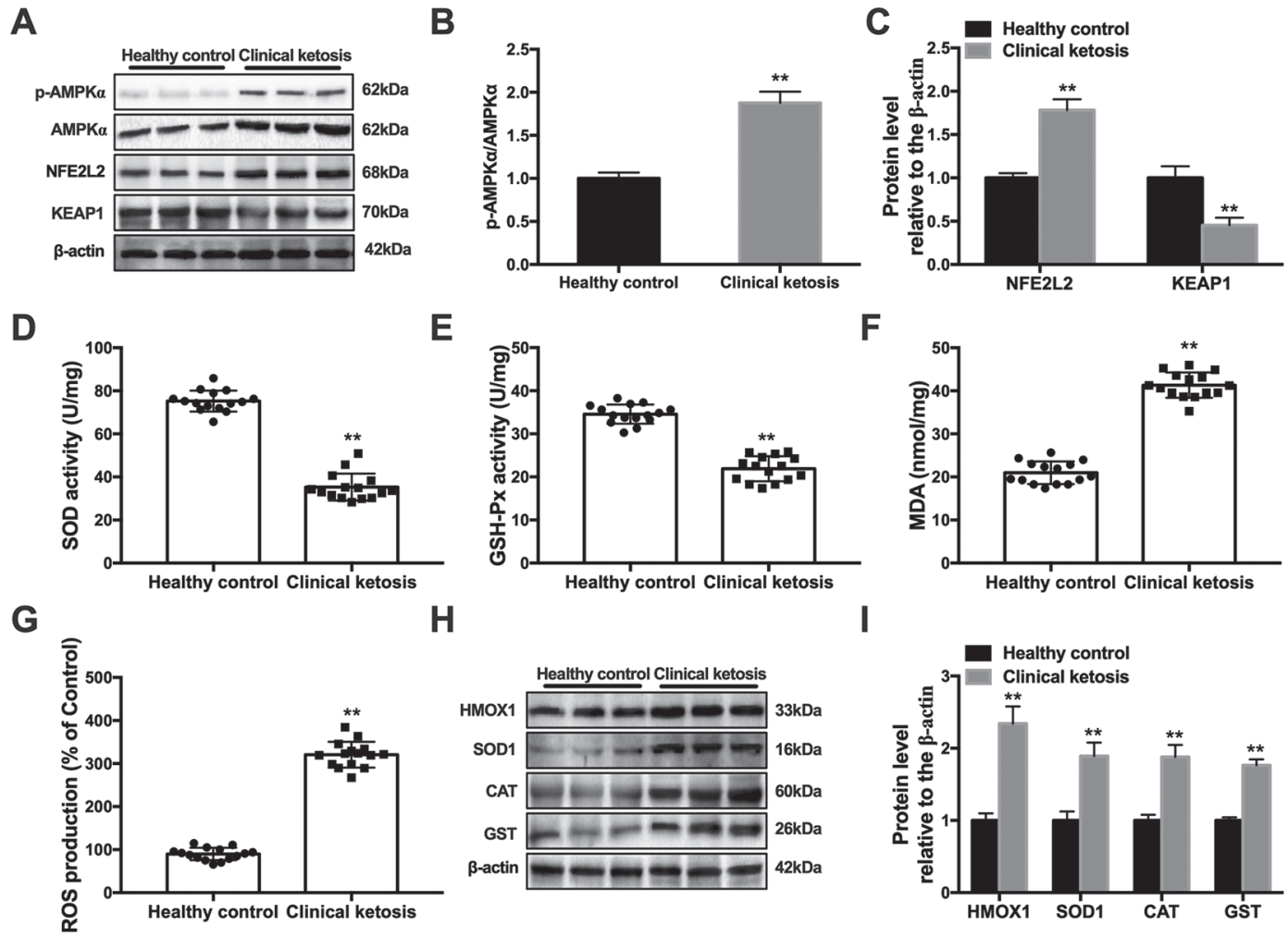

E

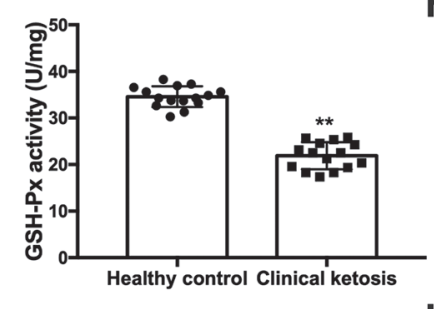

H

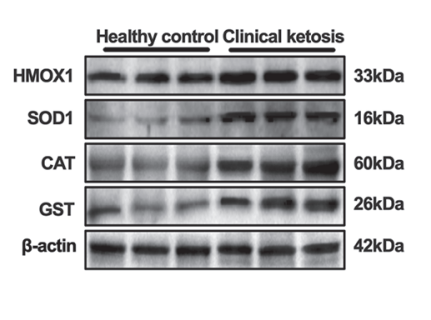

$\mathbf{F}$

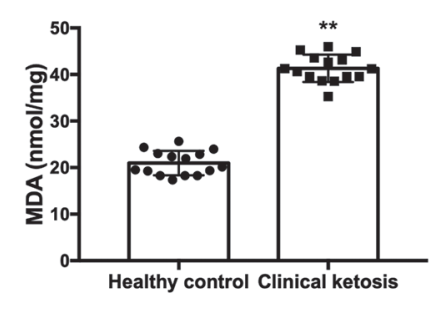

I

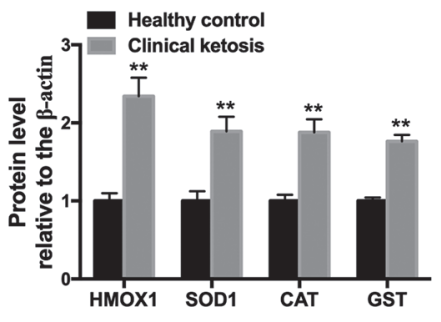

Figure 1. Abundance of adenosine 5'-monophosphate-activated protein kinase (AMPK $\alpha$ ), nuclear factor erythroid-derived 2-like 2 (NFE2L2), and Kelch-like ECH-associated protein 1 (KEAP1) in adipose tissue of healthy $(\mathrm{n}=15)$ and clinically ketotic $(\mathrm{n}=15)$ cows. $(\mathrm{A})$ Western blots analysis of AMPK $\alpha$, NFE2L2, and KEAP1. (B) Phosphorylation of AMPK $\alpha$ at threonine 172. (C) Protein abundance of NFE2L2 and KEAP1. (D) Superoxide dismutase (SOD) activity. (E) Glutathione peroxidase (GSH-Px) activity. (F) Malondialdehyde (MDA) content. (G) Reactive oxygen species (ROS) activity. (H) Western blot analysis of heme oxygenase 1 (HMOX1), superoxide dismutase 1 (SOD1), catalase (CAT), and glutathione-S-transferase (GST). (I) Protein abundance of HMOX1, SOD1, CAT, and GST. For all bar plots shown, data are expressed as mean \pm SEM. ${ }^{*} P<0.05,{ }^{* *} P<0.01$; statistical differences assessed by $t$-test. 
A
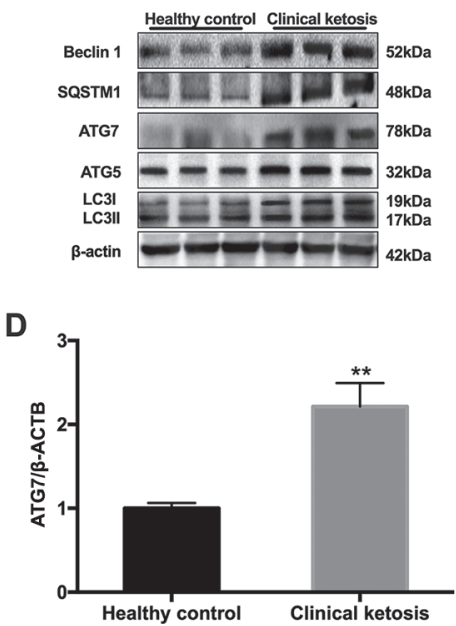

B
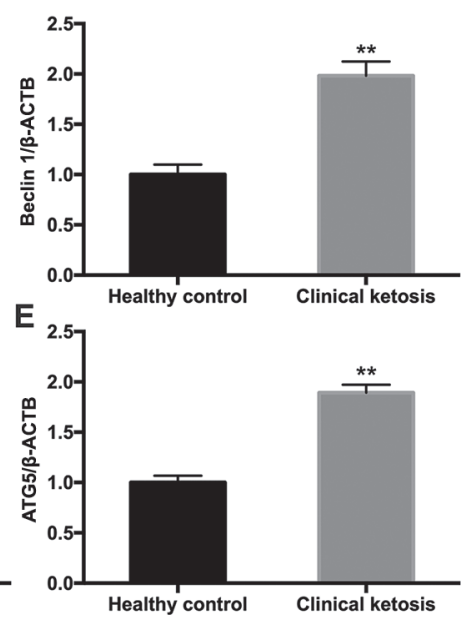

C

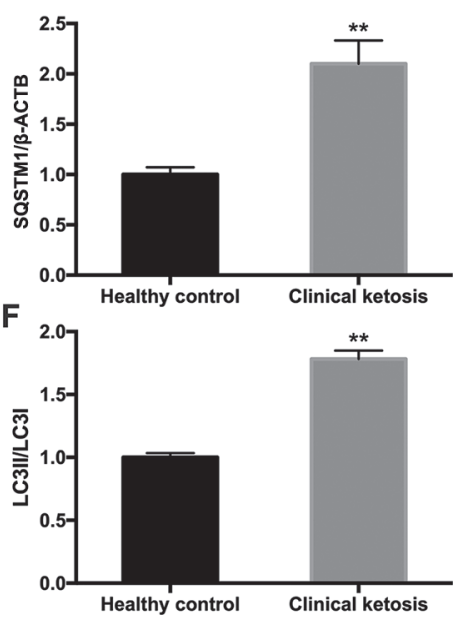

Figure 2. Abundance of proautophagy proteins in adipose tissue of healthy $(\mathrm{n}=15)$ and clinically ketotic $(\mathrm{n}=15)$ cows. (A) Representative Western blots of Beclin1, sequestosome 1 (SQSTM1), autophagy-related gene 7 (ATG7), autophagy-related gene 5 (ATG5), and light chain 3 (LC3). (B-F) Quantification of protein abundance of Beclin1, SQSTM1, ATG7, ATG5, and LC3. For all bar plots shown, data are expressed as mean \pm SEM. ${ }^{*} P<0.05,{ }^{*} P<0.01$; statistical differences assessed by $t$-test.

Table 2. Effects of varying concentrations of $\mathrm{H}_{2} \mathrm{O}_{2}(0,50,100,200$, or $400 \mu M)$ on abundance of AMPK and NFE2L2 pathways in bovine adipocytes

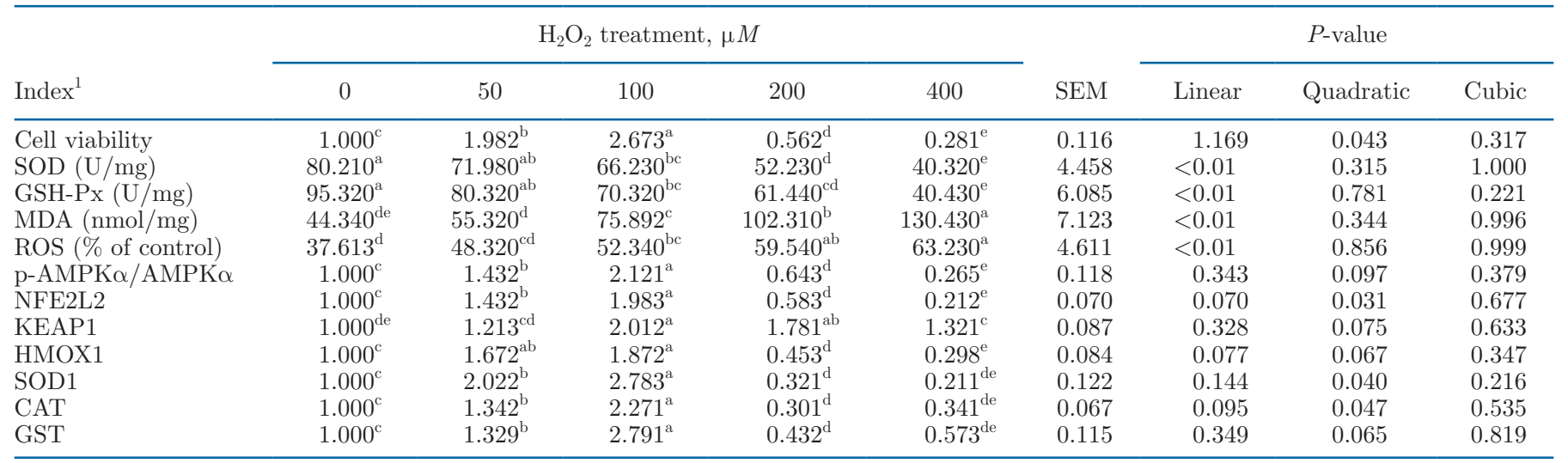

${ }^{\mathrm{a}-\mathrm{e}}$ Means in the same row not followed by the same lowercase superscript letters differ significantly $(P<0.05)$; differences were considered to be a statistical trend when $0.05<P<0.10$.

${ }^{1} \mathrm{SOD}=$ superoxide dismutase; GSH-Px = glutathione peroxidase; MDA = maleic dialdehyde; $\mathrm{ROS}=$ reactive oxygen species; AMPK = adenosine 5'-monophosphate-activated protein kinase; NFE2L2 = nuclear factor erythroid-derived 2-like 2; KEAP1 = Kelch-like ECH-associated protein 1; HMOX1 = heme oxygenase 1; SOD1 = superoxide dismutase 1; CAT = catalase; and GST = glutathione-S-transferase

Table 3. Effects of varying concentrations of $\mathrm{H}_{2} \mathrm{O}_{2}(0,50,100,200$, or $400 \mu M)$ on autophagy in bovine adipocytes

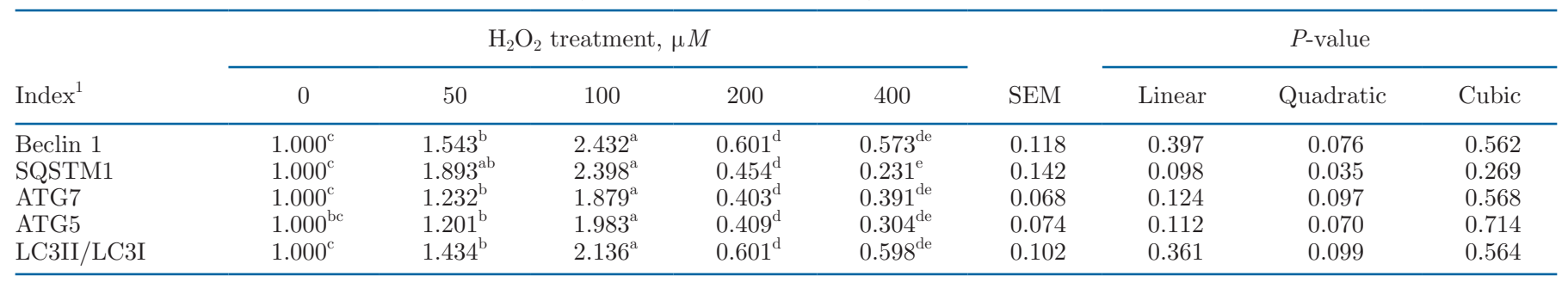

${ }^{\mathrm{a}-\mathrm{e}}$ Means in the same row not followed by the same lowercase superscript letters differ significantly $(P<0.05)$; differences were considered to be a statistical trend when $0.05<P<0.10$.

${ }^{1} \mathrm{SQSTM} 1=$ sequestosome $1 ; \mathrm{LC} 3=$ microtubule-associate protein light chain 3 . 
0.01, Figure 3A, B), whereas addition of ad-AMPK $\alpha-$ siRNA significantly downregulated the phosphorylation of AMPK $\alpha(P<0.01$, Figure 3C, D). Activation of AMPK upregulated protein abundance of NFE2L2 and attenuated the decrease of NFE2L2 induced by $\mathrm{H}_{2} \mathrm{O}_{2}(P<0.01$, Figure 3A, B $)$. A similar tendency was observed for protein abundance of downstream NFE2L2 targets including HMOX1, SOD1, CAT, and GST $(P<0.01$, Figure 3A, B). Furthermore, activation of AMPK downregulated protein abundance of KEAP1 compared with the control group $(P<0.01$, Figure 3A, B). However, treatment with ad-AMPKosiRNA decreased protein abundance of NFE2L2 and further exacerbated the downregulation of HMOX1, SOD1, CAT, and GST in $\mathrm{H}_{2} \mathrm{O}_{2}$-treated adipocytes $(P<0.01$, Figure 3C, D). Inhibition of AMPKa upregulated protein abundance of KEAP1 compared with the control group $(P<0.01$, Figure $3 \mathrm{C}, \mathrm{D})$. In the immunocytofluorescence analysis, treatment with A769662 increased NFE2L2 translocation to the nucleus, compared with the control group, whereas it was significantly decreased by $\mathrm{H}_{2} \mathrm{O}_{2}$ treatment (Supplemental Figure S1, https://dataverse.harvard.edu/ dataset.xhtml?persistentId=doi:10.7910/DVN/BA8WO4). Furthermore, activation of AMPK reversed the negative effect of $\mathrm{H}_{2} \mathrm{O}_{2}$ on NFE2L2 translocation to the nucleus (Supplemental Figure S1).

Activation of AMPK increased the activity of SOD and GSH-Px and attenuated the decrease of SOD and GSH-Px activity induced by $\mathrm{H}_{2} \mathrm{O}_{2}$ stimulation $(P<$ 0.01, Figure 4A, B). Activation of AMPK attenuated the increase of MDA and ROS induced by $\mathrm{H}_{2} \mathrm{O}_{2}(P<$ 0.01, Figure 4C, D). Inhibition of AMPKo decreased SOD and GSH-Px activity but increased production of MDA and ROS, and further exacerbated $\mathrm{H}_{2} \mathrm{O}_{2}$-induced downregulation of SOD and GSH-Px activity and overproduction of MDA and ROS $(P<0.01$, Figure $4 \mathrm{E}-\mathrm{H})$.

\section{Effects of AMPK on Autophagy in Bovine Adipocytes Under $\mathrm{H}_{2} \mathrm{O}_{2}$ Exposure}

Activation of AMPK upregulated protein abundance of proautophagy proteins (Beclin1, SQSTM1, ATG7, ATG5, and LC3II/LC3I) in bovine adipocytes and reversed the $\mathrm{H}_{2} \mathrm{O}_{2}$-induced decrease on abundance of proautophagy proteins $(P<0.01$, Figure $5 \mathrm{~A}-\mathrm{D})$. However, treatment with ad-AMPK $\alpha$-siRNA decreased protein abundance of autophagy-related genes and further exacerbated the downregulation of Beclin1, SQSTM1, ATG7, ATG5, and LC3II/LC3I in $\mathrm{H}_{2} \mathrm{O}_{2}$-stimulated bovine adipocytes $(P<0.01$, Figure $5 \mathrm{E}-\mathrm{H})$. In the immunocytofluorescence analysis, treatment with A769662 increased phosphorylation of SQSTM1 translocation to the nucleus when compared with the control group, whereas it was significantly decreased by $\mathrm{H}_{2} \mathrm{O}_{2}$ treatment (Supplemental Figure S2, https://dataverse. harvard.edu/dataset.xhtml?persistentId=doi:10.7910/ DVN/BA8WO4). Activation of AMPK reversed the negative effect of $\mathrm{H}_{2} \mathrm{O}_{2}$ on phosphorylation of SQSTM1 translocation to the nucleus (Supplemental Figure S2).

\section{DISCUSSION}

The intense lipid mobilization caused by severe negative energy balance (NEB) in transition cows leads to adipose tissue metabolic stress and increased susceptibility to ketosis (Kabara et al., 2014; Wankhade et al., 2017; Xu et al., 2019b). The regulating effect of AMPK, NFE2L2, and autophagy under oxidizing conditions are well characterized in human and animal models of oxidative stress (Kiffin et al., 2006; Ma, 2013; Wu et al., 2014). The present studies investigated changes in protein abundance of AMPK $\alpha$, NFE2L2-mediated antioxidant response, and proautophagy factors in adipose tissue of healthy and ketotic dairy cows. Our in vitro data indicated that AMPK alleviates adipocyte oxidative stress by inducing NFE2L2-mediated antioxidant response and autophagy.

\section{Antioxidant Responses in Adipose Tissue}

Previous studies have shown that NEB in the transition period triggers catabolic pathways, which, at the cellular level, increase the production of ROS (Pedernera et al., 2010; Celi, 2011). Importantly, biochemical alterations during NEB favor the onset of an oxidative stress state in high-yielding lactating cows with ketosis (Lacetera et al., 2005). The transcription factor NFE2L2 is a crucial cellular defense mechanism against oxidative stress. Under basal conditions, NFE2L2-dependent transcription is normally integrated with the negative regulator KEAP1 as an inactive complex. When cells are exposed to ROS, NFE2L2 bypasses KEAP1-mediated suppression and binds to antioxidant response elements on target genes (HMOX1, SOD1, CAT, and GST) to maintain cellular redox homeostasis (Kwak et al., 2003; Taguchi et al., 2011). The importance of NFE2L2 as a defense mechanism against oxidative damage in adipose tissue of ketotic cows was characterized in our previous experiments (Sun et al., 2019). In the present study, the greater abundance of HMOX1, SOD1, CAT, and GST, coupled with the lower abundance of KEAP1 in ketotic cows, confirmed the activation of the NFE2L2-KEAP1 antioxidant pathway within adipose tissue induced by oxidative stress. Furthermore, ketotic cows displayed higher ROS and MDA content, whereas GSH-Px and SOD activity was lower. The lower antioxidant activity in clinically ketotic cows might have been due to 

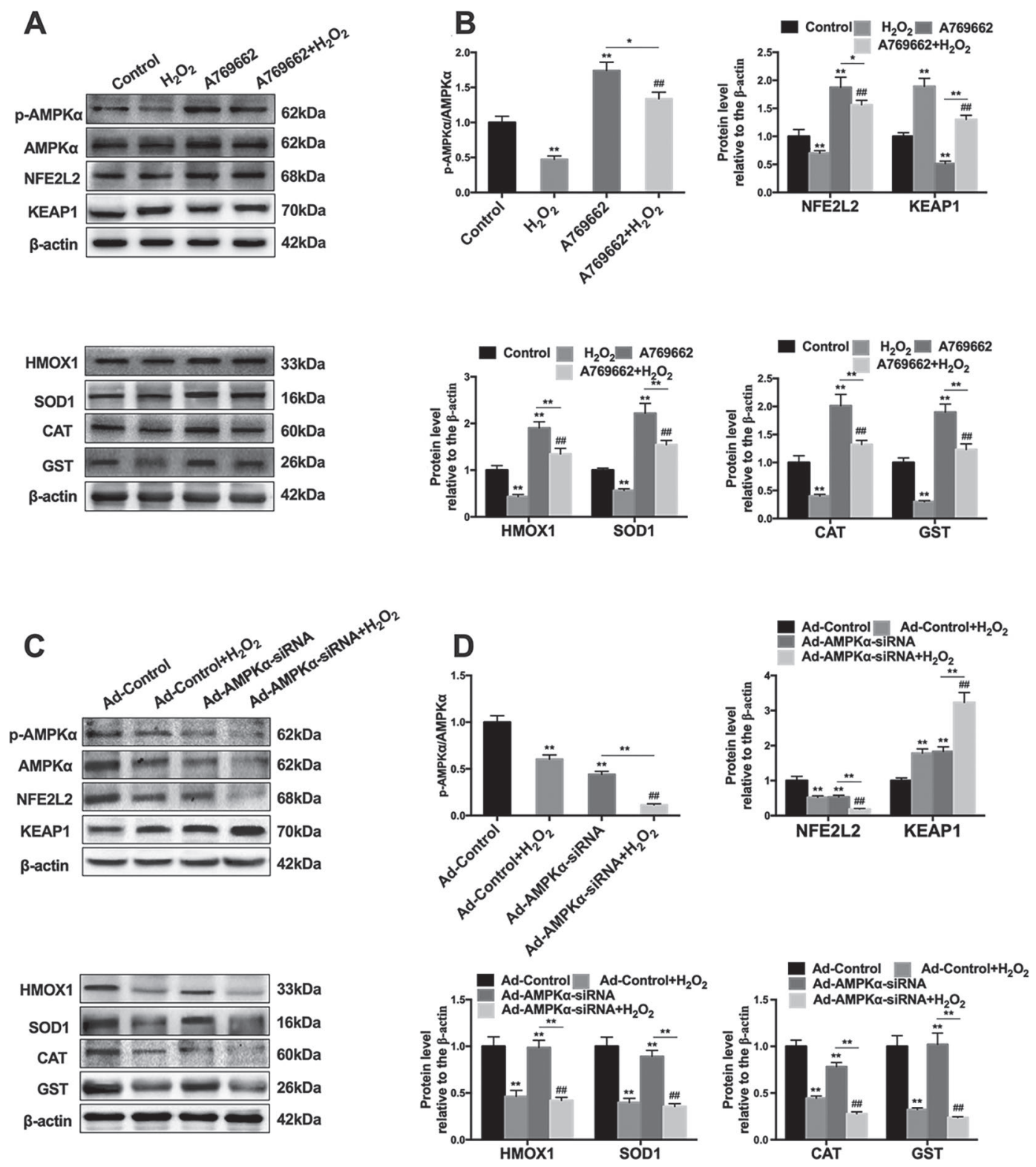

Figure 3. Effects of adenosine $5^{\prime}$-monophosphate-activated protein kinase (AMPK) on antioxidant response in bovine adipocytes during exposure to $\mathrm{H}_{2} \mathrm{O}_{2}$. Bovine adipocytes were treated with A769662 $(1 \mathrm{mM})$ for $3 \mathrm{~h}$ or adenovirus-mediated expression of small interfering RNA (ad-AMPKo-siRNA) for 48h, respectively, and further incubated in the absence or presence of $\mathrm{H}_{2} \mathrm{O}_{2}(200 \mu M)$ for the last $2 \mathrm{~h}$. (A, B) Effects of activation of AMPK on phosphorylation of AMPKo and protein abundance of nuclear factor erythroid-derived 2-like 2 (NFE2L2), Kelch-like ECH-associated protein 1 (KEAP1), heme oxygenase 1 (HMOX1), superoxide dismutase 1 (SOD1), catalase (CAT), and glutathione-S-trans-

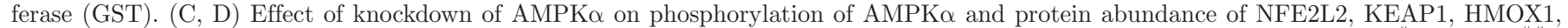
SOD1, CAT, and GST. For all bar plots shown, data are expressed as mean \pm SEM. ${ }^{*} P<0.05,{ }^{* *} P<0.01$ vs. control group or ${ }^{\#} P<0.05$, ${ }^{\# \#} P$ $<0.01$ vs. $\mathrm{H}_{2} \mathrm{O}_{2}$ group, by one-way ANOVA with subsequent Bonferroni correction.

impairment of the internal antioxidant defenses (Du et al., 2017).

\section{Autophagy in Adipose Tissue}

Autophagy, a cell survival process occurring in response to nutritional imbalances (Zhang et al., 2018b), is essential for integrated stress responses in all mam- malian tissues (Rao et al., 2007). Basal activation of autophagy is required to maintain cellular homeostasis under normal physiological conditions, as a protective mechanism against different forms of stress (Grumati et al., 2011). Thus, autophagy is critical in a wide range of normal physiological processes in which a defective flow of this process would result in various pathological defects (Cuervo and Macian, 2014; Papáčková and 
Cahová, 2014). In nonruminants, studies have shown that alterations in the autophagic molecular machinery are associated with metabolic syndrome (Papáčková and Cahová, 2014). Additionally, impaired autophagy, especially in obesity, may contribute to loss of function and cell death (Grumati et al., 2011). A previous study reported impaired liver autophagy activity in transition cows with severe fatty liver (Du et al., 2018). In the present study, the greater protein abundance of 5 distinct markers of autophagy, Beclin 1, SQSTM1, ATG3, ATG7, and the ratios of LC3II/LC3I in adipose tissue of ketotic cows, indicated an activation of autophagy. Thus, enhanced autophagy increased the "anti-stress" ability of adipose tissue in response to hyperketonemiainduced metabolic stress. An increase in autophagy at the molecular level may partly explain the inherent adaptation mechanism of adipose tissue in ketotic cows.

\section{AMPK and Antioxidant Responses}

AMP-activated protein kinase has emerged as a kinase that controls cellular redox-state and, hence, can protect cells against oxidative stress by reducing internal ROS accumulation (Hwang et al., 2008, 2014). Studies have shown that AMPK can be activated under some physiological and pathological conditions, which are characterized by a concomitant increase of intracellular levels of ROS (Han et al., 2010), suggesting an adaptive response to control oxidative stress. The first studies of AMPK in white adipose tissue were in relation to the control of lipolysis (Watt and Steinberg, 2008), suggesting that AMPK may be involved in the regulation of energy metabolism of bovine adipose tissue. Previous studies have shown that lipolysis in transition cows was associated with an increase in phosphorylation of AMPKo1 in adipose tissue (Locher et al., 2012); thus, the present data demonstrating increased abundance of AMPK as a function of rising ROS levels in adipose tissue of ketotic dairy cows is suggestive of a survival adaptation to control metabolic stress induced by NEB.

Because both AMPK and NFE2L2 are activated by oxidative stress and involved in the maintenance of redox homeostasis (Onken and Driscoll, 2010), we investigated whether AMPK is involved in redox homeostasis regulated by NFE2L2, and, more precisely, whether AMPK could induce activation of NFE2L2KEAP1 signaling. Treatment of bovine adipocytes with the AMPK activator A769662 led to an increase in HMOX1, SOD1, CAT, and GST abundance that was associated with an increase in the protein abundance
A

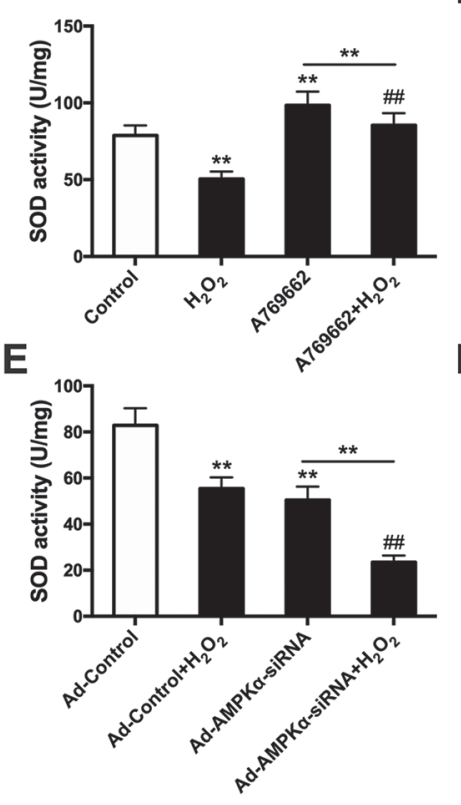

B
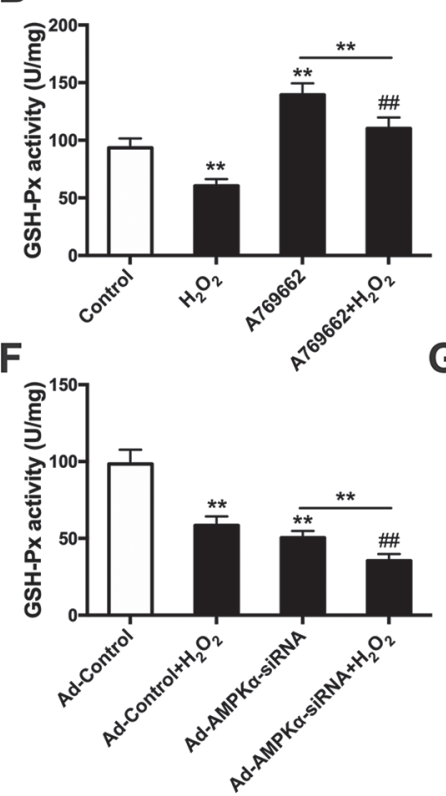

C
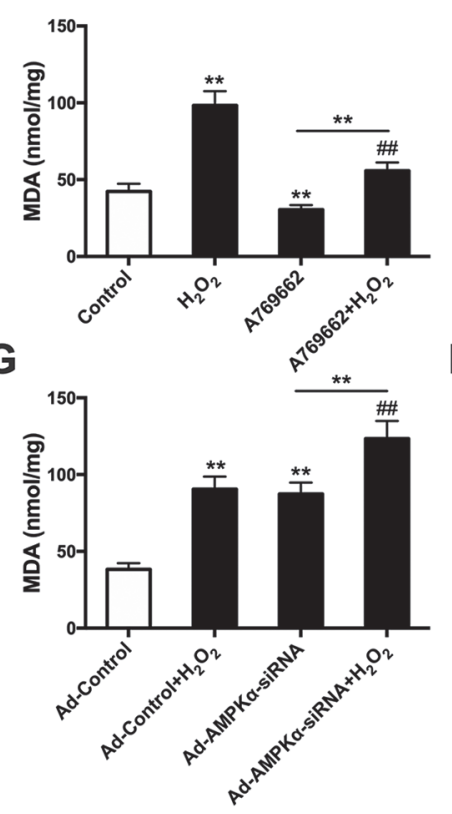

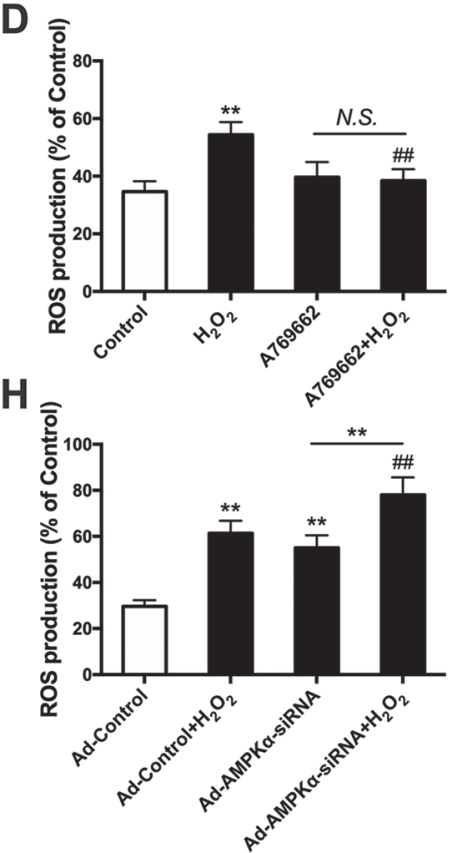

Figure 4. Effects of adenosine 5'-monophosphate-activated protein kinase (AMPK) on oxidative stress in bovine adipocytes during exposure to $\mathrm{H}_{2} \mathrm{O}_{2}$. Bovine adipocytes were treated with A769662 $(1 \mathrm{~m} M)$ or adenovirus-mediated expression of small interfering RNA (ad-AMPK $\alpha-$ siRNA) for $48 \mathrm{~h}$, respectively, and further incubated in the absence or presence of $\mathrm{H}_{2} \mathrm{O}_{2}(200 \mu M)$ for the last $2 \mathrm{~h}$. Effects of activation of AMPK on (A) superoxide dismutase (SOD) activity, (B) glutathione peroxidase (GSH-Px) activity, (C) malondialdehyde (MDA) content, and (D) reactive oxygen species (ROS) activity. Effects of knockdown of AMPKo on (E) SOD activity, (F) GSH-Px activity, (G) MDA content, and (H) ROS activity. For all bar plots shown, data are expressed as mean \pm SEM. ${ }^{*} P<0.05,{ }^{* *} P<0.01$ vs. control group or ${ }^{\#} P<0.05$, ${ }^{\# \#} P<0.01$ vs. $\mathrm{H}_{2} \mathrm{O}_{2}$ group, by one-way ANOVA with subsequent Bonferroni correction. 

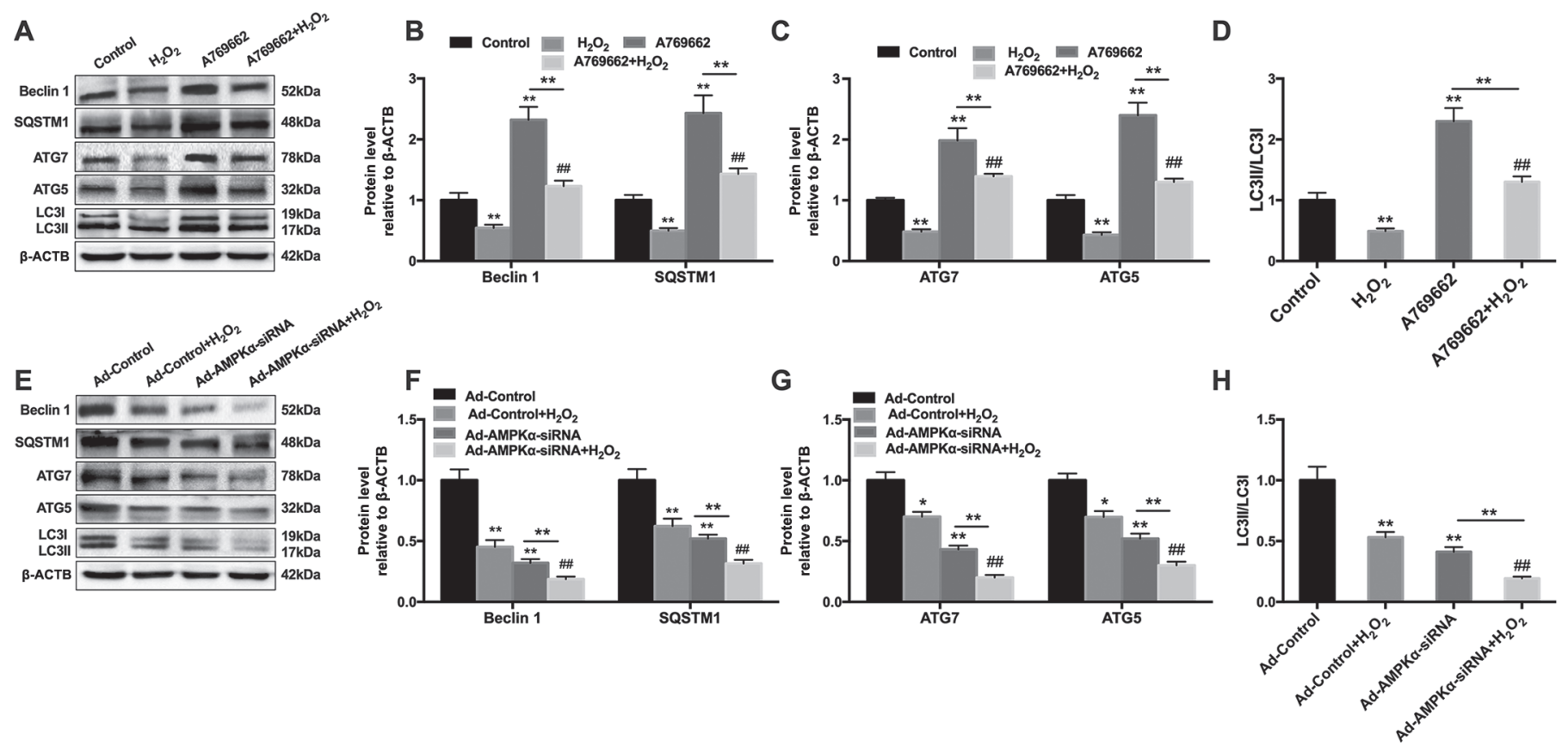

Figure 5. Effects of AMPK on autophagy in bovine adipocytes during exposure to $\mathrm{H}_{2} \mathrm{O}_{2}$. Bovine adipocytes were treated with A769662 $(1 \mathrm{mM})$ or adenovirus-mediated expression of small interfering RNA (ad-AMPKo-siRNA) for $48 \mathrm{~h}$, respectively, and further incubated in the absence or presence of $\mathrm{H}_{2} \mathrm{O}_{2}(200 \mu M)$ for the last $2 \mathrm{~h}$. (A-D) Effects of activation of AMPK on the protein abundance of Beclin1, sequestosome 1 (SQSTM1), autophagy-related gene 7 (ATG7), autophagy-related gene 5 (ATG5), and light chain 3 (LC3). (E-H) Effects of knockdown of AMPK $\alpha$ on the protein abundance of Beclin1, SQSTM1, ATG7, ATG5, and LC3. For all bar plots shown, data are expressed as mean \pm SEM. ${ }^{*} P<0.05,{ }^{* *} P<0.01$ vs. control group or ${ }^{\#} P<0.05,{ }^{\# \#} P<0.01$ vs. $\mathrm{H}_{2} \mathrm{O}_{2}$ group, by one-way ANOVA with subsequent Bonferroni correction.

of NFE2L2. In agreement with those data, inhibition of AMPK by ad-AMPK $\alpha$-siRNA suppressed activation of NFE2L2 and abundance of its downstream target genes. The immunocytochemical analysis indicated that NFE2L2 was predominantly located in the cytoplasm of control cells. However, A769662 treatment promoted nuclear localization of NFE2L2, confirming the functional role of AMPK in its nuclear accumulation. Hence, the nuclear accumulation of NFE2L2 elicited by activation of AMPK may have been due to a decrease in NFE2L2 level in the NFE2L2-KEAP1 binding pool within adipocytes.

\section{AMPK and Autophagy}

In the present study, the activation of AMPK was very effective in promoting a reduction in the levels of ROS and MDA under $\mathrm{H}_{2} \mathrm{O}_{2}$ stimulation, which was accompanied by the induction of proautophagy proteins. In addition, treatment with ad-AMPK $\alpha$-siRNA further accelerated the excessive accumulation of ROS and MDA, which led to the depletion of antioxidant activity, resulting in oxidative stress in bovine adipocytes. These data underscored a positive association between AMPK and the induction of autophagy in bovine adipocytes. Although the exact mechanisms responsible for this positive association could not be discerned, the downregulation of autophagy activity suggests that AMPK can mediate its activation in bovine adipocytes. In agreement with our results, previous studies have validated that treatment of endothelial cells with 2-deoxyglucose, an AMPK agonist by inhibiting glycolysis, increased AMPK phosphorylation and induction of autophagy. However, overexpression of CAT or treatment of cells with superoxide scavengers NAC and Tempol, respectively, reversed the induction of autophagy (Miceli and Jazwinski, 2005; Srivastava et al., 2009). Thus, AMPK-mediated autophagy may be a potential therapeutic target for the prevention and treatment of oxidative stress during ketosis in early-lactating dairy cows.

\section{CONCLUSIONS}

Enhanced antioxidant responses and autophagy activity may act as adaptive mechanisms within adipose tissue in response to metabolic challenges such as ketosis. In bovine adipocytes, AMPK $\alpha$ promotes nuclear accumulation of NFE2L2, suggesting an important role of this energy-sensing enzyme in the control of oxidative stress by increasing antioxidant capacity and autophagy activity. 


\section{ACKNOWLEDGMENTS}

This work was supported by the National Program on Key Research Project of China (Beijing, China; project no. 2017YFD0502206) and the National Natural Science Foundation of China (Beijing, China; grant no. 31672622). The authors have stated no conflicts of interest.

\section{REFERENCES}

Auciello, F. R., F. A. Ross, N. Ikematsu, and D. G. Hardie. 2014 Oxidative stress activates AMPK in cultured cells primarily by increasing cellular AMP and/or ADP. FEBS Lett. 588:3361-3366. https://doi.org/10.1016/j.febslet.2014.07.025.

Celi, P. 2011. Oxidative stress in ruminants. Pages 191-231 in Studies on Veterinary Medicine. L. Mandelker and P. Vajdovich, ed. Humana Press, Totowa, NJ.

Chen, M., J. J. Loor, Q. Zhai, Y. Liang, H. Yu, X. Du, T. Shen, Z. Fang, Z. Shi, X. Wang, Y. Zhu, Y. Song, G. Liu, X. Li, Z. Wang, and X. Li. 2020. Short communication: Enhanced autophagy activity in liver tissue of dairy cows with mild fatty liver. J. Dairy Sci. 103:3628-3635. https://doi.org/10.3168/jds.2019-17457.

Contreras, G. A., C. Strieder-Barboza, and W. Raphael. 2017. Adipose tissue lipolysis and remodeling during the transition period of dairy cows. J. Anim. Sci. Biotechnol. 8:41. https://doi.org/10 $.1186 / \mathrm{s} 40104-017-0174-4$.

Cuervo, A. M., and F. Macian. 2014. Autophagy and the immune function in aging. Curr. Opin. Immunol. 29:97-104. https://doi .org/10.1016/j.coi.2014.05.006.

Day, E. A., R. J. Ford, and G. R. Steinberg. 2017. AMPK as a therapeutic target for treating metabolic diseases. Trends Endocrinol. Metab. 28:545-560. https://doi.org/10.1016/j.tem.2017.05.004.

Drackley, J. K. 1999. Biology of dairy cows during the transition period: The final frontier? J. Dairy Sci. 82:2259-2273. https://doi .org/10.3168/jds.S0022-0302(99)75474-3.

Du, X., G. Liu, J. J. Loor, Z. Fang, R. Bucktrout, Y. Yang, Q. Ye, Z. Shi, T. Shen, X. Wang, Z. Peng, C. Zhao, B. Lv, D. Xing, Y. Zhu, X. Li, and X. Li. 2018. Impaired hepatic autophagic activity in dairy cows with severe fatty liver is associated with inflammation and reduced liver function. J. Dairy Sci. 101:11175-11185. https: /doi.org/10.3168/jds.2018-15120.

Du, X., Z. Shi, Z. Peng, C. Zhao, Y. Zhang, Z. Wang, X. Li, G. Liu, and X. Li. 2017. Acetoacetate induces hepatocytes apoptosis by the ROS-mediated MAPKs pathway in ketotic cows. J. Cell. Physiol. 232:3296-3308. https://doi.org/10.1002/jcp.25773.

Ferguson, J. D., D. T. Galligan, and N. Thomsen. 1994. Principal descriptors of body condition score in Holstein cows. J. Dairy Sci. 77:2695-2703. https://doi.org/10.3168/jds.S0022-0302(94)77212 $-\mathrm{X}$.

Fleming, A., T. Noda, T. Yoshimori, and D. C. Rubinsztein. 2011. Chemical modulators of autophagy as biological probes and potential therapeutics. Nat. Chem. Biol. 7:9-17. https://doi.org/10 $.1038 /$ nchembio. 500 .

Goff, J. P., and R. L. Horst. 1997. Physiological changes at parturition and their relationship to metabolic disorders. J. Dairy Sci. 80:1260-1268. https://doi.org/10.3168/jds.S0022-0302(97)76055 -7 .

Grumati, P., L. Coletto, A. Schiavinato, S. Castagnaro, E. Bertaggia, M. Sandri, and P. Bonaldo. 2011. Physical exercise stimulates autophagy in normal skeletal muscles but is detrimental for collagen VI-deficient muscles. Autophagy 7:1415-1423. https://doi.org/10 .4161/auto.7.12.17877.

Han, Y., Q. Wang, P. Song, Y. Zhu, and M.-H. Zou. 2010. Redox regulation of the AMP-activated protein kinase. PLoS One 5:e15420. https://doi.org/10.1371/journal.pone.0015420.
Hardie, D. G. 2015. AMPK: positive and negative regulation, and its role in whole-body energy homeostasis. Curr. Opin. Cell Biol. 33:1-7. https://doi.org/10.1016/j.ceb.2014.09.004.

He, C., H. Zhu, H. Li, M. H. Zou, and Z. Xie. 2013. Dissociation of Bcl-2-Beclin1 complex by activated AMPK enhances cardiac autophagy and protects against cardiomyocyte apoptosis in diabetes. Diabetes 62:1270-1281. https://doi.org/10.2337/db12-0533.

Hwang, A. B., E. A. Ryu, M. Artan, H. W. Chang, M. H. Kabir, H. J. Nam, D. Lee, J. S. Yang, S. Kim, W. B. Mair, C. Lee, S. S. Lee, and S. J. Lee. 2014. Feedback regulation via AMPK and HIF1 mediates ROS-dependent longevity in Caenorhabditis elegans. Proc. Natl. Acad. Sci. USA 111:E4458-E4467. https://doi.org/10 $.1073 /$ pnas.1411199111.

Hwang, J. T., D. Y. Kwon, O. J. Park, and M. S. Kim. 2008. Resveratrol protects ROS-induced cell death by activating AMPK in H9c2 cardiac muscle cells. Genes Nutr. 2:323-326. https://doi.org/10 .1007/s12263-007-0069-7.

Kabara, E., L. M. Sordillo, S. Holcombe, and G. A. Contreras. 2014. Adiponectin links adipose tissue function and monocyte inflammatory responses during bovine metabolic stress. Comp. Immunol. Microbiol. Infect. Dis. 37:49-58. https://doi.org/10.1016/j.cimid .2013.10.007.

Kiffin, R., U. Bandyopadhyay, and A. M. Cuervo. 2006. Oxidative stress and autophagy. Antioxid. Redox Signal. 8:152-162. https:// doi.org/10.1089/ars.2006.8.152.

Kim, J., M. Kundu, B. Viollet, and K. L. Guan. 2011. AMPK and mTOR regulate autophagy through direct phosphorylation of Ulk1. Nat. Cell Biol. 13:132-141. https://doi.org/10.1038/ncb2152.

Kroemer, G., G. Mariño, and B. Levine. 2010. Autophagy and the integrated stress response. Mol. Cell 40:280-293. https://doi.org/ 10.1016/j.molcel.2010.09.023.

Kwak, M. K., N. Wakabayashi, K. Itoh, H. Motohashi, M. Yamamoto, and T. W. Kensler. 2003. Modulation of gene expression by cancer chemopreventive ditiolethiones through the Keap1-Nrf2 pathway: Identification of novel gene clusters for cell survival. J. Biol. Chem. 278:8135-8145. https://doi.org/10.1074/jbc.M211898200.

Lacetera, N., D. Scalia, U. Bernabucci, B. Ronchi, D. Pirazzi, and A. Nardone. 2005. Lymphocyte functions in overconditioned cows around parturition. J. Dairy Sci. 88:2010-2016. https://doi.org/10 .3168/jds.S0022-0302(05)72877-0.

Li, X., G. Li, X. Du, X. Sun, Z. Peng, C. Zhao, Q. Xu, A. M. Abdelatty, F. F. Mohamed, Z. Wang, and G. Liu. 2020. Increased autophagy mediates the adaptive mechanism of the mammary gland in dairy cows with hyperketonemia. J. Dairy Sci. 103:2545-2555. https://doi.org/10.3168/jds.2019-16910.

Locher, L. F., J. Rehage, N. Khraim, U. Meyer, S. Dänicke, K. Hansen, and K. Huber. 2012. Lipolysis in early lactation is associated with an increase in phosphorylation of adenosine monophosphate-activated protein kinase (AMPK) $\alpha 1$ in adipose tissue of dairy cows. J. Dairy Sci. 95:2497-2504. https://doi.org/10.3168/jds.2011-4830.

Loor, J. J., G. Bertoni, A. Hosseini, J. R. Roche, and E. Trevisi. 2013. Functional welfare - Using biochemical and molecular technologies to understand better the welfare state of peripartal dairy cattle. Anim. Reprod. Sci. 53:931-953. https://doi.org/10.1071/ AN12344.

Loor, J. J., R. E. Everts, M. Bionaz, H. M. Dann, D. E. Morin, R. Oliveira, S. L. Rodriguez-Zas, J. K. Drackley, and H. A. Lewin. 2007. Nutrition-induced ketosis alters metabolic and signaling gene networks in liver of periparturient dairy cows. Physiol. Genomics 32:105-116. https://doi.org/10.1152/physiolgenomics.00188.2007.

Ma, Q. 2013. Role of nrf2 in oxidative stress and toxicity. Annu. Rev. Pharmacol. Toxicol. 53:401-426. https://doi.org/10.1146/annurev -pharmtox-011112-140320.

McNamara, J. P. 1994. Lipid metabolism in adipose tissue during lactation: A model of a metabolic control system. J. Nutr. 124(Suppl. 8):1383S-1391S. https://doi.org/10.1093/jn/124.suppl_8.1383S.

Miceli, M. V., and S. M. Jazwinski. 2005. Common and cell typespecific responses of human cells to mitochondrial dysfunction. Exp. Cell Res. 302:270-280. https://doi.org/10.1016/j.yexcr.2004 .09 .006 . 
Mizunoe, Y., Y. Sudo, N. Okita, H. Hiraoka, K. Mikami, T. Narahara, A. Negishi, M. Yoshida, R. Higashibata, S. Watanabe, H. Kaneko, D. Natori, T. Furuichi, H. Yasukawa, M. Kobayashi, and Y. Higami. 2017. Involvement of lysosomal dysfunction in autophagosome accumulation and early pathologies in adipose tissue of obese mice. Autophagy 13:642-653. https://doi.org/10.1080/15548627 .2016 .1274850 .

Mizushima, N., and M. Komatsu. 2011. Autophagy: Renovation of cells and tissues. Cell 147:728-741. https://doi.org/10.1016/j.cell 2011.10.026

Mottillo, E. P., E. M. Desjardins, J. D. Crane, B. K. Smith, A. E. Green, S. Ducommun, T. I. Henriksen, I. A. Rebalka, A. Razi, K. Sakamoto, C. Scheele, B. E. Kemp, T. J. Hawke, J. Ortega, J. G. Granneman, and G. R. Steinberg. 2016. Lack of adipocyte AMPK exacerbates insulin resistance and hepatic steatosis through brown and beige adipose tissue function. Cell Metab. 24:118-129. https:/ /doi.org/10.1016/j.cmet.2016.06.006.

NRC. 2001. Nutrient Requirements of Dairy Cattle. National Academies Press, Washington, DC. https://doi.org/10.17226/9825.

Onken, B., and M. Driscoll. 2010. Metformin induces a dietary restriction-like state and the oxidative stress response to extend C. elegans healthspan via AMPK, LKB1, and SKN-1. PLoS One 5:e8758. https://doi.org/10.1371/journal.pone.0008758.

Papáčková, Z., and M. Cahová. 2014. Important role of autophagy in regulation of metabolic processes in health, disease and aging. Physiol. Res. 63:409-420. https://doi.org/10.33549/physiolres .932684 .

Pedernera, M., P. Celi, S. C. García, H. E. Salvin, I. Barchia, and W. J. Fulkerson. 2010. Effect of diet, energy balance and milk production on oxidative stress in early-lactating dairy cows grazing pasture. Vet. J. 186:352-357. https://doi.org/10.1016/j.tvjl.2009 .09.003.

Rao, R. P., C. Yuan, J. C. Allegood, S. S. Rawat, M. B. Edwards, X. Wang, J. A. H. Merrill, U. Acharya, and J. K. Acharya. 2007. Ceramide transfer protein function is essential for normal oxidative stress response and lifespan. Proc. Natl. Acad. Sci. USA 104:11364-11369. https://doi.org/10.1073/pnas.0705049104.

Srivastava, S., F. Diaz, L. Iommarini, K. Aure, A. Lombes, and C. T. Moraes. 2009. PGC- $1 \alpha / \beta$ induced expression partially compensates for respiratory chain defects in cells from patients with mitochondrial disorders. Hum. Mol. Genet. 18:1805-1812. https://doi .org $/ 10.1093 / \mathrm{hmg} / \mathrm{ddp} 093$.

Sun, X., X. Li, H. Jia, J. J. Loor, R. Bucktrout, Q. Xu, Y. Wang, X Shu, J. Dong, R. Zuo, L. Yang, G. Liu, and X. Li. 2019. Effect of heat-shock protein B7 on oxidative stress in adipocytes from preruminant calves. J. Dairy Sci. 102:5673-5685. https://doi.org/ 10.3168 /jds.2018-15726.

Taguchi, K., H. Motohashi, and M. Yamamoto. 2011. Molecular mechanisms of the Keap1-Nrf2 pathway in stress response and cancer evolution. Genes Cells 16:123-140. https://doi.org/10.1111/j.1365 $-2443.2010 .01473 . \mathrm{x}$

Van der Drift, S. 2013. Ketosis in dairy cows: Etiologic factors, monitoring, treatment. PhD thesis. Faculty of Veterinary Medicine, Utrecht University, Utrecht, the Netherlands.

Vanholder, T., J. Papen, R. Bemers, G. Vertenten, and A. C. Berge. 2015. Risk factors for subclinical and clinical ketosis and association with production parameters in dairy cows in the Netherlands. J. Dairy Sci. 98:880-888. https://doi.org/10.3168/jds.2014-8362.
Vernon, R. G. 2003. Adipose tissue: An expanding role in the regulation of energy metabolism. Pages 451-464 in Progress in Research on Energy and Protein Metabolism. W. B. Souffrant and C. C. Metges, ed. Wageningen Academic Publishers, Wageningen, the Netherlands.

Wankhade, P. R., A. Manimaran, A. Kumaresan, S. Jeyakumar, K. P. Ramesha, V. Sejian, D. Rajendran, and M. R. Varghese. 2017. Metabolic and immunological changes in transition dairy cows: A review. Vet. World 10:1367-1377. https://doi.org/10.14202/ vetworld.2017.1367-1377.

Watt, M. J., and G. R. Steinberg. 2008. Regulation and function of triacylglycerol lipases in cellular metabolism. Biochem. J. 414:313325. https://doi.org/10.1042/BJ20080305.

Wu, S. B., Y. T. Wu, T. P. Wu, and Y. H. Wei. 2014. Role of AMPKmediated adaptive responses in human cells with mitochondrial dysfunction to oxidative stress. Biochim. Biophys. Acta 1840:13311344. https://doi.org/10.1016/j.bbagen.2013.10.034

Xu, Q. H. Jia, L. Ma, G. Liu, C. Xu, Y. Li, X. Li, and X. Li. 2019a. All-trans retinoic acid inhibits lipopolysaccharide-induced inflammatory responses in bovine adipocytes via TGF $31 / \mathrm{Smad} 3$ signaling pathway. BMC Vet. Res. 15:48. https://doi.org/10.1186/ s12917-019-1791-2

Xu, Q., X. Li, L. Ma, J. J. Loor, D. N. Coleman, H. Jia, G. Liu, C. Xu, Y. Wang, and X. Li. 2019b. Adipose tissue proteomic analysis in ketotic or healthy Holstein cows in early lactation. J. Anim. Sci. 97:2837-2849. https://doi.org/10.1093/jas/skz132.

Zhang, S., G. Liu, C. Xu, L. Liu, Q. Zhang, Q. Xu, H. Jia, X. Li, and X. Li. 2018a. Perilipin 1 mediates lipid metabolism homeostasis and inhibits inflammatory cytokine synthesis in bovine adipocytes. Front. Immunol. 9:467. https://doi.org/10.3389/fimmu.2018 .00467 .

Zhang, Y., J. R. Sowers, and J. Ren. 2018b. Targeting autophagy in obesity: from pathophysiology to management. Nat. Rev. Endocrinol. 14:356-376. https://doi.org/10.1038/s41574-018-0009-1.

Zhang, Y., X. Zeng, and S. Jin. 2012. Autophagy in adipose tissue biology. Pharmacol. Res. 66:505-512. https://doi.org/10.1016/j.phrs .2012.09.004.

Zhu, Y., Y. Guan, J. J. Loor, X. Sha, D. N. Coleman, C. Zhang, X. Du, Z. Shi, X. Li, Z. Wang, G. Liu, and X. Li. 2019. Fatty acidinduced endoplasmic reticulum stress promoted lipid accumulation in calf hepatocytes, and endoplasmic reticulum stress existed in the liver of severe fatty liver cows. J. Dairy Sci. 102:7359-7370. https://doi.org/10.3168/jds.2018-16015.

Zou, T., B. Wang, Q. Yang, J. M. de Avila, M. J. Zhu, J. You, D. Chen, and M. Du. 2018. Raspberry promotes brown and beige adipocyte development in mice fed high-fat diet through activation of AMP-activated protein kinase (AMPK) $\alpha 1$. J. Nutr. Biochem. 55:157-164. https://doi.org/10.1016/j.jnutbio.2018.02.005.

\section{ORCIDS}

Qiushi Xu ๑ https://orcid.org/0000-0003-3012-6475

Juan J. Loor @ https://orcid.org/0000-0003-1586-4365

Yusheng Liang ๑ https://orcid.org/0000-0003-1751-6823

Chuang Xu ๑ https://orcid.org/0000-0002-0377-1439 